\title{
Effect of Volume-Oriented Versus Flow-Oriented Incentive Spirometry on Chest Wall Volumes, Inspiratory Muscle Activity, and Thoracoabdominal Synchrony in the Elderly
}

\author{
Adriana C Lunardi PT PhD, Desiderio C Porras, Renata CC Barbosa PT MSc, \\ Denise M Paisani PT PhD, Cibele CB Marques da Silva PT MSc, \\ Clarice Tanaka PT PhD, and Celso RF Carvalho PT PhD
}

\begin{abstract}
BACKGROUND: Aging causes physiological and functional changes that impair pulmonary function. Incentive spirometry is widely used for lung expansion, but the effects of volume-oriented incentive spirometry (VIS) versus flow-oriented incentive spirometry (FIS) on chest wall volumes, inspiratory muscle activity, and thoracoabdominal synchrony in the elderly are poorly understood. We compared VIS and FIS in elderly subjects and healthy adult subjects. METHODS: Sixteen elderly subjects $(9$ women, mean \pm SD age $70.6 \pm 3.9 \mathrm{y}$, mean \pm SD body mass index $23.8 \pm 2.5 \mathrm{~kg} /$ $\mathrm{m}^{2}$ ) and 16 healthy adults $(8$ women, mean \pm age $25.9 \pm 4.3 \mathrm{y}$, mean \pm body mass index $23.6 \pm 2.4 \mathrm{~kg} /$ $\mathbf{m}^{2}$ ) performed quiet breathing, VIS, and FIS in randomized sequence. Chest wall kinematics (via optoelectronic plethysmography) and inspiratory muscle activity (via surface electromyography) were assessed simultaneously. Synchrony between the superior thorax and abdominal motion was calculated (phase angle). RESULTS: In the elderly subjects both types of incentive spirometry increased chest wall volumes similarly, whereas in the healthy adult subjects VIS increased the chest wall volume more than did FIS. FIS and VIS triggered similar lower thoracoabdominal synchrony in the elderly subjects, whereas in the healthy adults FIS induced lower synchrony than did VIS. FIS required more muscle activity in the elderly subjects to create an increase in chest wall volume. CONCLUSIONS: Incentive spirometry performance is influenced by age, and the differences between elderly and healthy adults response should be considered in clinical practice. Key words: breathing exercises; physical therapy; incentive spirometry; elderly; respiratory mechanics; electromyography; chest wall; biomechanics; lung volumes. [Respir Care 2014;59(3):420-426. () 2014 Daedalus Enterprises]
\end{abstract}

\section{Introduction}

The aging process is associated with a progressive reduction in physiological capacity, which can compromise several organs and systems and impair their function. In the respiratory system, age-related functional changes result from a decrease in the static elastic recoil of the lungs, chest wall compliance, and respiratory muscle strength. ${ }^{1-3}$

The authors are affiliated with the Department of Physical Therapy, School of Medicine, University of São Paulo, São Paulo, Brazil.

This study was partly supported by grants 2010/50120-4 and 2010/19196-4 from Fundação de Amparo à Pesquisa do Estado de São Paulo, São Paulo, Brazil.

The authors have disclosed no conflicts of interest.
This decrease in the static elastic recoil of the lungs is related to changes in the quantity and composition of the supporting structures within the lung parenchyma. ${ }^{4}$

The reduced physiological capacity of the respiratory system with aging can predispose vulnerable individuals to an increased risk for respiratory diseases, such as respiratory insufficiency, atelectasis, and respiratory infection..$^{5,6}$ Some breathing exercises are commonly used in the treat-

\footnotetext{
Correspondence: Celso RF Carvalho PT PhD, Department of Physical Therapy, School of Medicine, University of São Paulo, Rua Cipotânea 51, São Paulo, Brazil, 05360-160. E-mail: cscarval@usp.br.
}

DOI: $10.4187 /$ respcare. 02665 
ment and prevention of aging-related respiratory conditions.

Incentive spirometry is a type of deep breathing exercise that is widely used for lung expansion and the prevention of pulmonary complications in children, adults, and the elderly.7,8 Two types of incentive spirometry are commercially available: volume-oriented incentive spirometry (VIS) and flow-oriented incentive spirometry (FIS). Both VIS and FIS are used to encourage the patient to inhale to lung capacity through maximal inspiration aided with visual feedback. These maneuvers increase transpulmonary pressure and therefore increase chest-wall volume. ${ }^{9}$

Parreira et $\mathrm{al}^{10}$ and Paisani et al ${ }^{11}$ showed that VIS promotes a greater chest wall volume with a larger abdominal contribution than does FIS in healthy adult subjects. In addition, Chang et al $(2010)^{7}$ and Parreira et al $(2005)^{10}$ suggested that the inspiratory flow, rather than the type of incentive spirometry, determines the breathing pattern and the respiratory muscle activation in this population. ${ }^{7,10}$ However, to the best of our knowledge, the effects of VIS and FIS in elderly subjects has not been evaluated. We compared the effects of VIS and FIS on chest wall volume, inspiratory muscle activity, and thoracoabdominal synchrony in healthy elderly and adult subjects.

\section{Methods}

This randomized controlled clinical trial was approved by our hospital's research ethics committee (study 606/ 11 ), and all subjects provided written informed consent.

\section{Subjects}

We recruited 22 healthy elderly ( $>65$ y old) and 18 healthy adult ( $<40$ y old) subjects, matched by body mass index and height, from a university population. We excluded patients with deformities of the chest wall or spine, $\mathrm{FEV}_{1}$ or FVC $<80 \%$ of predicted, or forced expiratory flow during the middle half of the FVC maneuver $<60 \%$ of predicted, ${ }^{11}$ respiratory symptoms (dyspnea, cough, breathlessness), cardiac disease, or current smoking (Fig. 1).

\section{Devices}

The tested FIS was Respiron (NCS, Barueri, São Paulo, Brazil) and the tested VIS was Voldyne 5000 (Hudson RCI/Teleflex Medical, Research Triangle Park, North Carolina), which we chose because they are commonly used in clinical practice. With the Respiron the inhalation raises a ball inside a column, which serves as visible feedback about the inspiratory flow. With the Voldyne the inhala-

\section{QUICK LOOK}

\section{Current knowledge}

It is not known whether volume-oriented and floworiented incentive spirometry differently affect chest wall volumes, inspiratory muscle activity, or thoracoabdominal synchrony in the elderly.

\section{What this paper contributes to our knowledge}

The 2 types of incentive spirometry similarly increased chest wall volumes and lower thoracoabdominal synchrony in healthy elderly subjects, whereas in healthy adult subjects volume-oriented incentive spirometry increased chest wall volume more. Flow-oriented incentive spirometry required more muscle activity in the elderly subjects to create an increase in chest wall volume.

tion raises a piston plate, which serves as visible feedback about the inspiratory volume.

\section{Protocol}

The assessment of thoracoabdominal kinematics and inspiratory muscle activity was performed during quiet breathing, followed by either VIS or FIS, guided by a respiratory therapist. The order of use (VIS or FIS) was randomly determined via sealed envelopes that were sequentially numbered by an independent researcher. All of the subjects performed 8 quiet breaths, followed by 8 deep breaths, with FIS and VIS, in the order specified by the randomization, with an interval of at least 2 min between the devices. During incentive spirometry the subject was asked to perform 8 breaths with a slow inhalation to raise the ball (FIS) or the piston plate (VIS) and to sustain the inflation for at least 5 seconds, followed by normal exhalation. ${ }^{12,13}$ An average of 6 homogeneous respiratory cycles was considered for the data analysis, which was performed by a bioengineer. The chest wall volumes and inspiratory muscle activity outcomes were assessed concurrently.

\section{Thoracoabdominal Kinematics}

Thoracoabdominal kinematics were evaluated with optoelectronic plethysmography (OEP System, BTS, Garbagnate Milanese, Italy), as previously described. ${ }^{12}$ This equipment is based on 8 video cameras (solid-state chargecoupled devices) operating at 100 frames per second and synchronized with a flashing infrared light-emitting diode. Four cameras are positioned in front of the subject and 4 


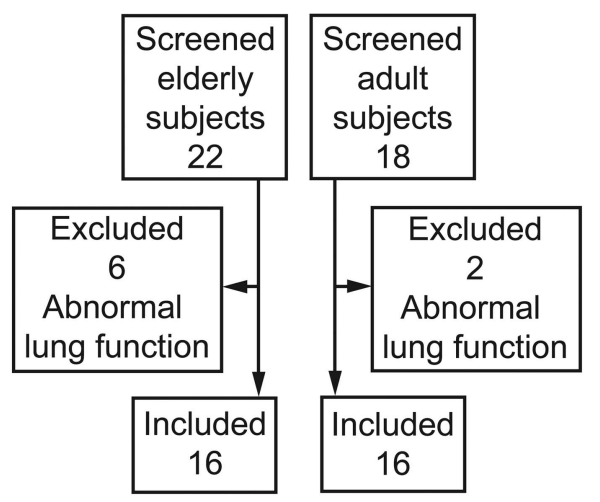

Fig. 1. Flow chart.

behind. Eighty-nine retro-reflective markers are placed on the anterior and posterior sides of the trunk, according to the protocol previously described by Aliverti et al (2009). ${ }^{14}$ Three-dimensional calibration of the equipment was performed, based on the manufacturer's recommendations. Next, to evaluate the thoracoabdominal kinematics around the chest wall, the assessment was performed with the subject seated on a chair, without back support. The following variables were measured.

Total Chest Wall and Compartmental Volumes. The optoelectronic plethysmograph's software reconstructs the 3-dimensional position of each marker during the measurements, and computes the volume variations of the whole chest wall and the thoracic and abdominal compartments. The values for the superior and inferior thorax and abdomen are expressed as absolute values and percentages.

Inspiratory Flow. The mean inspiratory flow is quantified by dividing the total chest wall volume by the total inspiratory time.

Time Variables. The mean inspiratory time, total breathing cycle time, and the ratio of the inspiratory time to the total breathing cycle time (the duty cycle) are quantified.

Thoracoabdominal Asynchrony. The thoracoabdominal asynchrony is calculated based on the abdominal phase angle of the superior thorax, per the method of Agostoni et al (1966). ${ }^{15}$ The phase angle is calculated as the lag time between the peaks of the superior thorax and the abdominal signals, divided by the total breathing cycle time, multiplied by $360^{\circ}$.

\section{Inspiratory Muscle Activity}

The activity of the sternocleidomastoid and external superior and inferior intercostal muscles was assessed via electromyography (EMG) (FreeEMG, BTS, Garbagnate

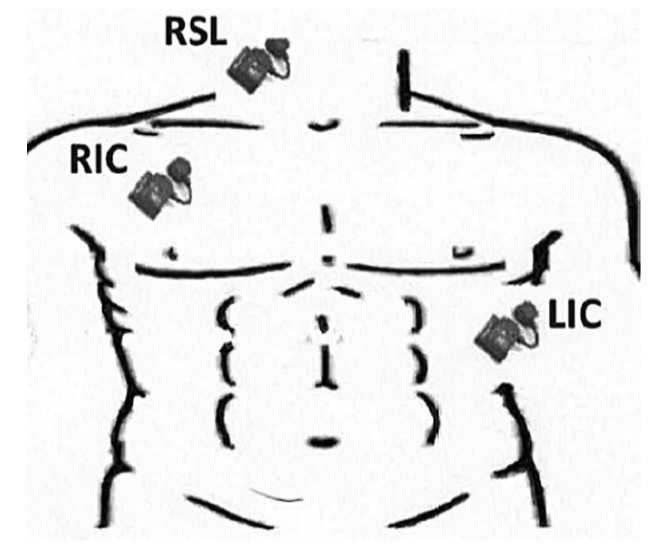

Fig. 2. Electrode placement. RSL = right sternocleidomastoid muscle. $\mathrm{RIC}=$ right external superior intercostal muscle. $\mathrm{LIC}=$ left external inferior intercostal muscle.

Milanese, Italy), simultaneously with the thoracoabdominal kinematics.

Electrode Position. Each probe was attached to 2 reusable bipolar superficial electrodes, consisting of $\mathrm{Ag} / \mathrm{AgCl}$ material and a conductive adhesive hydrogel (Maxicor, Brazil). The inter-electrode distance was $20 \mathrm{~mm}$. Before placing the electrode the skin was cleaned with an alcohol swab at the attachment sites to remove oils from the contact surface and thus decrease the impedance of the skin. The superficial electrodes were fixed on the muscle belly, away from the motor point and parallel to the direction of the muscle fibers, in accordance with the European standards for surface EMG of the noninvasive assessment of muscles. ${ }^{16}$ The right sternocleidomastoid electrode was placed on the muscle body, $5 \mathrm{~cm}$ from the mastoid process. ${ }^{17}$ For the external intercostal muscle of the right superior thorax the electrode was placed on the second anterior intercostal space. ${ }^{18}$ For the external intercostal muscle of the left inferior thorax electrodes were placed on the seventh and eighth anterior intercostal spaces. ${ }^{18}$ All of the electrode positions were determined in accordance with the best signal capture, and the EMG analyses were performed as recommended by Hermens et al (2000) (Fig. 2). ${ }^{16}$

Data Acquisition and Processing. Signals were obtained using an 8-channel EMG module with wireless probes, which had an acquisition frequency of 1,000 Hz. Each probe consisted of a mother electrode and a satellite electrode connected via a flexible cable, each fitted with a clip. The mother electrode contained an analog-to-digital converter (with a resolution of 16 bits), an antenna, and a battery. The satellite electrode contained a signalconditioning, low-pass filter with a frequency of $500 \mathrm{~Hz}$ and an amplifier with a gain range of $\pm 1.62 \mathrm{mV}$. All of 
Table 1. Subjects

\begin{tabular}{lccc}
\hline \hline & $\begin{array}{c}\text { Elderly } \\
(n=16)\end{array}$ & $\begin{array}{c}\text { Adult } \\
(n=16)\end{array}$ & $P$ \\
\hline Male, no. (\%) & $7(44)$ & $8(50)$ & .78 \\
Age, y & $70.6 \pm 2.3$ & $25.9 \pm 4.7$ & $<.001$ \\
Body mass index, $\mathrm{kg} / \mathrm{m}^{2}$ & $23.8 \pm 2.5$ & $23.6 \pm 2.4$ & .82 \\
Height, cm & $1.67 \pm 0.05$ & $1.67 \pm 0.10$ & .99 \\
FVC, \% predicted & $101 \pm 19$ & $105 \pm 12$ & .48 \\
FEV $_{1}, \%$ predicted & $113 \pm 21$ & $104 \pm 10$ & .13 \\
FEV $_{1} /$ FVC & $0.88 \pm 0.9$ & $0.85 \pm 0.5$ & .25
\end{tabular}

Values are mean \pm SD unles otherwise indicated.

the data were captured and analyzed with the EMG system's software.

In the post-processing stage we applied a Butterworth high-pass filter with a cutoff frequency of $20 \mathrm{~Hz}$, so the signal's frequency range was $20-500 \mathrm{~Hz}$. To detect the linear envelope of the EMG signal, the signal was fullwave rectified and low-pass filtered. The electrical activity of the sternocleidomastoid and upper and lower intercostal muscles are reported as root mean square values.

\section{Statistical Analysis}

The sample size calculation was performed based on the mean \pm SD difference between the pulmonary volumes generated by the VIS and the FIS $(475 \pm 71 \mathrm{~mL})$, with a target power of $80 \% .{ }^{10}$ The required sample size was 16 subjects per group. The normality of data distribution was tested with the Shapiro-Wilk test. The homoscedasticity between healthy adults and the elderly was tested with the $t$ test. The analyses of differences between quiet breathing and breathing using incentive spirometry within the groups were via analysis of variance, with the post hoc HolmSidak method. Differences were considered significant when $P<.05$.

\section{Results}

Sixteen elderly subjects and 16 healthy adult subjects were evaluated, and all of the subjects presented normal lung function (Table 1).

\section{Thoracoabdominal Volumes}

In both the elderly and healthy adult subjects, FIS and VIS induced similar volume increases in the chest wall, superior and inferior thorax, and abdominal compartments, compared to quiet breathing. However, in the elderly subjects FIS and VIS had the same effect, but in the adults
VIS caused a greater increase in the chest wall and abdominal compartments than did FIS (Table 2 and Fig. 3).

\section{Respiratory Cycles, Thoracoabdominal Synchrony, and Inspiratory Flow}

In the elderly subjects, neither FIS nor VIS significantly changed the inspiratory time or total breathing cycle time, compared to quiet breathing. In the adult subjects VIS increased the inspiratory time and total breathing cycle time, compared to FIS and quiet breathing (see Table 2). In both groups the inspiratory flow was higher during incentive spirometry than during quiet breathing, but there were no significant difference between the devices or groups (see Table 2).

In the elderly subjects both FIS and VIS induced lower thoracoabdominal synchrony (higher values) than did quiet breathing. In the adults only FIS significantly changed thoracoabdominal synchrony (see Table 2).

\section{Inspiratory Muscle Activity}

In both the elderly and adult subjects there were no significant differences in sternocleidomastoid or superior or inferior intercostal muscle electrical activity during FIS or VIS (see Table 2). However, during FIS the inspiratory muscles activity per chest wall volume was higher in the elderly subjects than it was in the adults (Fig. 4).

\section{Discussion}

VIS and FIS are widely used to reverse or prevent reductions in chest wall volumes, and incentive spirometry is employed in healthy adult subjects and the elderly as if the effect would be similar independent of the subject's age. In healthy adults, previous studies have reported that VIS induced greater chest wall expansion and abdominal displacement ${ }^{10,11,19}$ and lower inspiratory muscle activity ${ }^{9,11,20}$ and work of breathing ${ }^{21,22}$ than FIS. However, to the best of our knowledge the advice to use incentive spirometry has never been investigated in elderly subjects. This seems important because aging reduces chest wall compliance, decreases the size and number of respiratory muscle fibers, and causes changes in thoracoabdominal motion $^{23}$ that can alter performance during incentive spirometry.

In our elderly subjects FIS required greater inspiratory muscle activity to generate similar volumes than did VIS, whereas in our adult subjects there was no significant difference in inspiratory muscle activity between FIS and VIS (see Fig. 3). This suggest that the subject's age must be considered when prescribing incentive spirometry, especially in elderly subjects who have symptoms or signs of respiratory muscle wasting. Interestingly, this increase in 
Table 2. Respiratory Variables and Muscle Activity During Quiet Breathing and Incentive Spirometry

\begin{tabular}{|c|c|c|c|c|c|c|}
\hline & \multicolumn{3}{|c|}{ Elderly Subjects $(n=16)$} & \multicolumn{3}{|c|}{ Adult Subjects $(n=16)$} \\
\hline & $\begin{array}{l}\text { Quiet } \\
\text { Breathing }\end{array}$ & $\begin{array}{l}\text { Flow- } \\
\text { Oriented } \\
\text { Incentive } \\
\text { Spirometry }\end{array}$ & $\begin{array}{l}\text { Volume- } \\
\text { Oriented } \\
\text { Incentive } \\
\text { Spirometry }\end{array}$ & $\begin{array}{l}\text { Quiet } \\
\text { Breathing }\end{array}$ & $\begin{array}{l}\text { Flow- } \\
\text { Oriented } \\
\text { Incentive } \\
\text { Spirometry }\end{array}$ & $\begin{array}{l}\text { Volume- } \\
\text { Oriented } \\
\text { Incentive } \\
\text { Spirometry }\end{array}$ \\
\hline \multicolumn{7}{|l|}{ Volumes, L } \\
\hline Chest wall & $0.50 \pm 0.26$ & $1.23 \pm 0.61^{*}$ & $1.38 \pm 0.74 *$ & $0.66 \pm 0.20$ & $2.25 \pm 1.04 \dagger$ & $2.84 \pm 1.20 \dagger+$ \\
\hline Superior thorax & $0.14 \pm 0.10$ & $0.35 \pm 0.19 *$ & $0.39 \pm 0.21 *$ & $0.24 \pm 0.12$ & $0.89 \pm 0.45 \dagger$ & $1.07 \pm 0.63 \dagger$ \\
\hline Inferior thorax & $0.08 \pm 0.05$ & $0.29 \pm 0.19^{*}$ & $0.29 \pm 0.20^{*}$ & $0.14 \pm 0.07$ & $0.55 \pm 0.28 \dagger$ & $0.68 \pm 0.36 \dagger$ \\
\hline Abdomen & $0.29 \pm 0.18$ & $0.60 \pm 0.36^{*}$ & $0.71 \pm 0.46^{*}$ & $0.28 \pm 0.09$ & $0.82 \pm 0.48 \dagger$ & $1.09 \pm 0.14 \dagger+$ \\
\hline Inspiratory time, $\mathrm{s}$ & $1.61 \pm 0.57$ & $1.66 \pm 0.82$ & $1.93 \pm 1.24$ & $2.12 \pm 0.92$ & $2.37 \pm 1.15$ & $3.55 \pm 2.57 \dagger+$ \\
\hline Total breathing cycle time, $\mathrm{s}$ & $3.61 \pm 0.87$ & $3.50 \pm 2.21$ & $4.30 \pm 2.24$ & $4.95 \pm 1.21$ & $5.51 \pm 2.72$ & $8.32 \pm 4.16 \dagger+$ \\
\hline $\begin{array}{l}\text { Inspiratory time/total breathing cycle time } \\
\text { Inspiratory flow, } \mathrm{L} / \mathrm{s}\end{array}$ & $0.44 \pm 0.07$ & $0.49 \pm 0.06$ & $0.44 \pm 0.10$ & $0.43 \pm 0.11$ & $0.43 \pm 0.07$ & $0.39 \pm 0.10$ \\
\hline Chest wall/inspiratory time & $0.31 \pm 0.10$ & $0.78 \pm 0.23^{*}$ & $0.80 \pm 0.35^{*}$ & $0.34 \pm 0.13$ & $0.99 \pm 0.28 \dagger$ & $0.94 \pm 0.45 \dagger$ \\
\hline $\begin{array}{l}\text { Synchrony (phase angle: superior thorax } \times \\
\text { abdomen) }\end{array}$ & $4.72 \pm 3.73$ & $17.65 \pm 14.63^{*}$ & $10.63 \pm 7.91 *$ & $7.25 \pm 10.9$ & $29.40 \pm 29.9 \dagger$ & $11.94 \pm 12.4 \ddagger$ \\
\hline \multicolumn{7}{|l|}{ Muscle activity, $10^{-3} \mathrm{mV}$} \\
\hline Right sternocleidomastoid & $5.20 \pm 1.8$ & $48.64 \pm 24.3^{*}$ & $33.9 \pm 24.61 * \S$ & $4.45 \pm 1.90$ & $33.74 \pm 32.1 \dagger$ & $30.9 \pm 25.4 \dagger$ \\
\hline Right intercostals & $9.19 \pm 7.3$ & $19.36 \pm 10.3^{*}$ & $15.82 \pm 9.80^{*}$ & $5.59 \pm 1.60$ & $21.76 \pm 22.7 \dagger$ & $19.9 \pm 25.4 \dagger$ \\
\hline Left intercostals & $6.34 \pm 2.6$ & $11.57 \pm 7.2^{*}$ & $11.69 \pm 6.30^{*}$ & $6.79 \pm 3.40$ & $15.36 \pm 8.9 \dagger$ & $14.6 \pm 8.5 \dagger$ \\
\hline \multicolumn{7}{|c|}{$\begin{array}{l}\text { Values are mean } \pm \mathrm{S} D \text {. } \\
* P<.05 \text { versus quiet breathing in the elderly group. } \\
\dagger P<.05 \text { versus quiet breathing in the healthy adult group. } \\
¥ P<.05 \text { versus flow-oriented incentive spirometry in the healthy adult group. } \\
\S P=.25 \text { versus flow-oriented incentive spirometry in the elderly group. }\end{array}$} \\
\hline
\end{tabular}

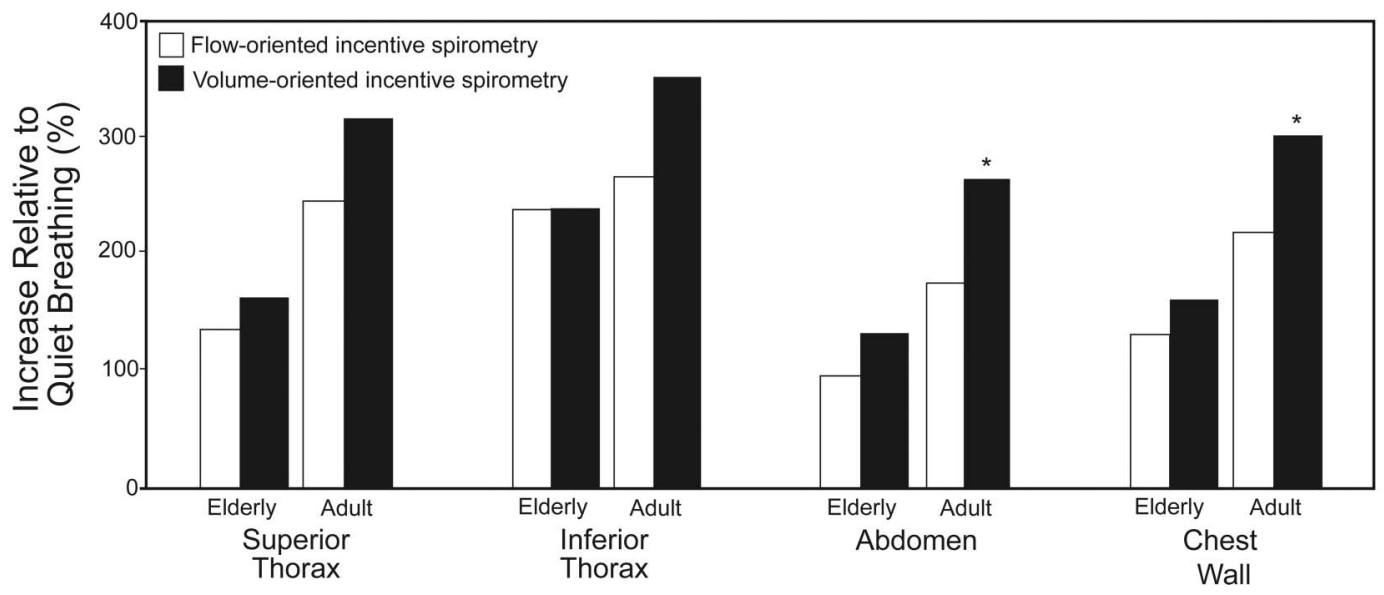

Fig. 3. Percent increases in thoracic and abdominal compartment volumes during flow-oriented versus volume-oriented incentive spirometry in healthy adult and elderly subjects. ${ }^{*} P<.05$ for volume-oriented versus flow-oriented.

respiratory muscle activity was observed even in healthy elderly subjects, and might be explained by the elderly having reduced lung volumes and chest wall capacities, ${ }^{23,24}$ which place the diaphragm at a mechanical disadvantage in generating effective contraction..$^{1,25}$

FIS and VIS induced similar volumes and displacement in all the thoracoabdominal compartments in the elderly, whereas in the adult subjects VIS induced greater abdom- inal displacement than did FIS. ${ }^{10,11}$ Contrary to the findings of previous studies, our adult subjects did not have higher sternocleidomastoid activity during FIS. ${ }^{10,11}$ The difference between our results and those studies might be due to differences in how the subjects were advised to perform incentive spirometry, or to different EMG electrode positioning. In our study the electrode positioning was standardized and the same researcher oriented all the 


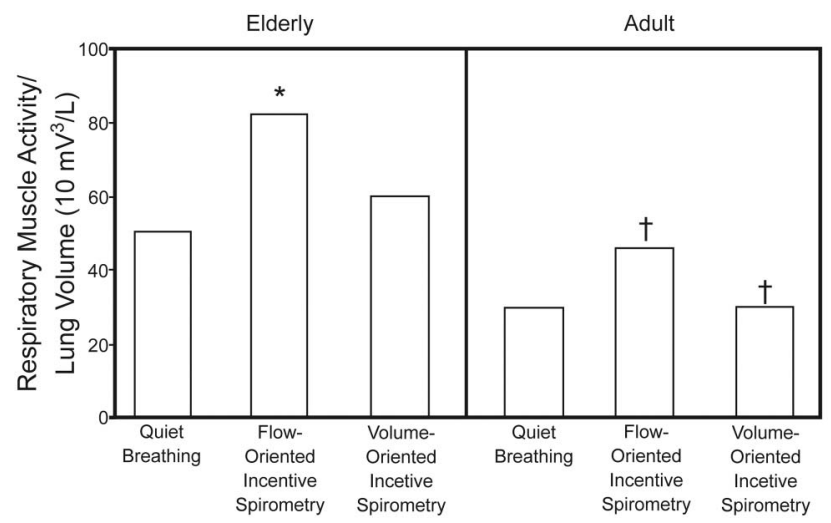

Fig. 4. Ratio of total respiratory muscle activity to total inspired lung volume. ${ }^{*} P=<.05$ compared to quiet breathing and volume-oriented incentive spirometry. $\dagger P<.05=$ compared to flow-oriented incentive spirometry and volume-oriented incentive spirometry in healthy elderly subjects.

subjects similarly. In addition, electrode positioning was performed as previously described in the literature, ${ }^{17,18}$ and the EMG signal capture and analyses were performed per international guidelines. ${ }^{16}$

Also contrary to other studies in healthy adult subjects, ${ }^{9,26}$ VIS and FIS induced similar inspiratory flow and similarly reduced thoracoabdominal synchrony in the elderly. Interestingly, our elderly subjects had shorter inspiratory time than did our adult subjects, which can be explained by aging-related physiological changes in the lung and respiratory system, which require greater inspiratory muscle activity that can reduce thoracoabdominal synchrony (higher values). Our hypothesis is supported by the finding that the inspiratory time in the adult subjects was twice that in the elderly (see Table 2), and, as a consequence, during VIS the elderly could not expand the chest wall as much as the healthy adult subjects could.

\section{Limitations}

First, the effects of incentive spirometry were evaluated in subjects with normal lung function; however, our research group is conducting studies in other populations, to increase the practical applicability of incentive spirometry. Second, muscle activity was evaluated with surface EMG, and there is no consensus about electrode positioning for the respiratory muscles. We placed the electrodes according to previous studies by experts in this field. In contrast, we used a novel technology for thoracoabdominal analysis, and it is the only available equipment that allows for simultaneous measurement of volume displacement and respiratory muscle activity.

Our results provide important information using incentive spirometry in clinical practice, despite that the prevention and treatment of respiratory complications using these devices as monotherapy remains poorly understood. ${ }^{27}$ It might also be important for future studies to evaluate incentive spirometry, either as monotherapy or associated with other respiratory care techniques, in various clinical situations, to determine appropriate therapy for the elderly.

\section{Conclusions}

FIS and VIS provided similar increases in chest wall and compartmental volumes in the elderly, but FIS required greater inspiratory muscle activity. Therefore, when evaluating a patient for incentive spirometry the clinician should consider the patient's age and clinical condition, as well as the goal of therapy.

\section{REFERENCES}

1. Janssens JP, Pache JC, Nicod LP. Physiological changes in respiratory function associated with age. Eur Respir J 1999;13(1):197-205.

2. Watsford ML, Mark L, Murphy AJ, Pine MJ. The effects of ageing on respiratory muscle function and performance in older adults. J Sci Med Sport 2007;10(1):36-44.

3. Fragoso CAV, Gill TM, McAay G, Yaggi HK, Van Ness PH, Concato J. Respiratory impairment and mortality in older persons: a novel spirometric approach. J Invest Med 2011;59(7):1089-1095.

4. Meyer FJ, Lossnitzer D, Kristen AV, Schoene AM, Kubler W, Katus HA, Borst MM. Respiratory muscle dysfunction in idiopathic pulmonary arterial hypertension. Eur Respir J 2005;25(1):125-130.

5. Sprung J, Gajic O, Warner DO. Review article: age related alterations in respiratory function - anesthetic considerations. Can J Anesth 2006;53(12):1244-1257.

6. Fernandes CR, Ruiz Neto PP. [The respiratory system and the elderly: anesthetic implications]. Rev Bras Anestesiol 2002;52(4):461470. Article in Portuguese.

7. Chang AT, Palmer KR, McNaught J, Thomas PJ. Inspiratory flow rate, not type of incentive spirometry device, influences chest wall motion in healthy individuals. Physiother Theory Pract 2010;26(6): 385-392.

8. Qaseem A, Snow V, Fitterman N, Hornbake ER, Lawrence VA, Smetana GW, et al. Risk assessment for and strategies to reduce perioperative pulmonary complications for patients undergoing noncardiothoracic surgery: a guideline from the American College of Physicians. Ann Intern Med 2006;144(8):575-580.

9. Tomich GM, França DC, Diório ACM, Brito RR, Sampaio RF, Parreira VF. Breathing pattern, thoracoabdominal motion and muscular activity during three breathing exercises. Braz J Med Biol Res 2007;40(10):1409-1417.

10. Parreira VF, Tomich GM, Brito RR, Sampaio RF. Assesment of tidal volume and thoracoabdominal motion using volume and floworiented incentive spirometers in healthy subjects. Braz J Med Biol Res 2005;38(7):1105-1111.

11. Paisani DM, Lunardi AC, Marques da Silva CCB, Porras DC, Tanaka $\mathrm{C}$, Carvalho CRF. Volume rather than flow incentive spirometry is effective in improving chest wall expansion and abdominal displacement using optoelectronic plethysmography. Respir Care 2013;58(8): 1360-1366.

12. Miller MR, Hankinson J, Brusasco V, Burgos F, Casaburi R, Coates A, et al; ATS/ERS Task Force. Standardisation of spirometry. Eur Respir J 2005;26(2):319-338.

13. Restrepo RD, Wettstein R, Wittnebel L, Tracy M. Incentive Spirometry: 2011. Respir Care 2011;56(10):1600-1604. 


\section{Comparison of Distinct Incentive SpIROMETERS}

14. Aliverti A, Carlesso E, Raffaele Dellacà R, Pelosi $\mathrm{P}$, Chiumello D, Pedotti A, Gattinoni L. Chest wall mechanics during pressure support ventilation. Crit Care 2006;10(2):1-10.

15. Aliverti A, Quaranta M, Chakrabarti B, Albuquerque ALP, Calverley PM. Paradoxical movement of the lower ribcage at rest and during exercise in COPD patients. Eur Respir J 2009;33(1):49-60.

16. Agostoni E, Mognoni P. Deformation of the chest wall during breathing efforts. J Appl Physiol 1966;21(6):1827-1832.

17. Hermens HJ, Freriks B, Disselhorst-Klug C, Rau G. Development of recommendations for SEMG sensors and sensor placement procedures. J Electromyogr Kinesiol 2000;10(5):361-374.

18. Kallenberg LA, Preece S, Nester C, Hermens HJ. Reproductibility of MUAP properties in array surface EMG recordings of the upper trapezius and sternocleidomastoid muscle. J Electromyogr Kinesiol 2009;19(6):536-542.

19. Maarsingh EJ, van Eykern LA, Sprikkelman AB, Hoekstra MO, van Aalderen WM. Respiratory muscle activity measured with a noninvasive EMG technique: technical aspects and reproducibility. J Appl Physiol 2000;88(6):1955-1961.

20. Ho SC, Chiang LL, Cheng HF, Lin HC, Sheng DF, Kuo HP, Lin HC. The effect of incentive spirometry on chest expansion and breathing work in patients with chronic obstructive airway diseases: comparison of two methods. Chang Gung Med J 2000;23(2):73-79.

21. Weindler J, Kiefer RT. The efficacy of postoperative incentive spirometry is influenced by the device-specific imposed work of breathing. Chest 2001;119(6):1858-1864.

22. Mang H, Obermayer A. Imposed work of breathing during sustained maximal inspiration: Comparison of six incentive spirometers. Respir Care 1989;34(12):1122-1128.

23. Verschakelen JA, Demedts MG. Normal thoracoabdominal motions. Influence of sex, age, posture, and breath size. Am J Respir Crit Care Med 1995;151(2 Pt 1):399-405.

24. Kim J, Sapienza CM. Implications of expiratory muscle strength training for rehabilitation of the elderly: tutorial. J Rehab Res Dev 2005;42(2):211-224

25. Sharma G, Goodwin J. Effect of aging on respiratory system physiology and immunology. J Clin Intervent Aging 2006;1(3):253-260.

26. Chan ED, Welsch CH. Geriatric respiratory medicine. Chest 1998; 114(6):1704-1733

27. Carvalho CRF, Paisani DM, Lunardi AC. Incentive spirometry in major surgeries: a systematic review. Braz J Physical Ther 2011; 15(5):343-350. 